\title{
Economic Pessimism and Political Punishment in 2020 - CORRIGENDUM
}

\section{Brad Lockerbie}

doi: https://doi.org/10.1017/S1049096520001444 Published by Cambridge University Press, 15 October 2020

In the original publication of this article, the reference entry for Yagci et al. 2020 contained errors. The correct reference is as follows.

Yagci, Alper H., and Cem Oyvat. 2020. "Partisanship, Media, and the Objective Economy: Sources of Individual-Level Economic Assessments."

Electoral Studies 66: 102135.

The author regrets the error. The original article has been updated. "

\section{REFERENCE}

Lockerbie, Brad. "Economic Pessimism and Political Punishment in 2020." PS: Political Science \& Politics 54, no. 1 (2021): 67-69. doi:10.1017/S1049096520001444. 